\title{
Mycoplasma felifaucium, a New Species Isolated from the Respiratory Tract of Pumas
}

\author{
By A URIOL C. HILL \\ Medical Research Council Experimental Embryology and Teratology Unit, \\ Woodmansterne Road, Carshalton, Surrey SM5 4EF, UK
}

(Received 11 October 1985; revised 27 January 1986)

Mycoplasmas isolated from the throats of three pumas (Felis concolor) were each cloned and examined in detail. All three were serologically and biologically indistinguishable from each other, and were serologically distinct from 83 recognized Mycoplasma and Acholeplasma species. They were designated as a new species, Mycoplasma felifaucium, with strain PU (NCTC 11703) as the type strain.

\section{INTRODUCTION}

Mycoplasma spp. have been isolated from a wide variety of animals, birds and plants. Most of the wild animals have not been examined for their mycoplasmal flora, but two reports have been published on mycoplasma isolation from captive large felines, including lions, lynx, pumas and tigers (Heyward et al., 1969; Hill, 1975). The tiger isolates and some of those recovered from lions and pumas were typed as Mycoplasma arginini (Tully et al., 1972; Hill, 1975). The other strains from lions have not been fully characterized but are serologically distinct from the puma isolates.

The puma strains cultivated by Hill (1975) had been isolated during a survey carried out to investigate the mycoplasmal flora of large felines, by examining the upper respiratory tract of pumas, when they were anaesthetized for surgical or other procedures. This paper is concerned with their further characterization.

\section{METHODS}

Mycoplasma strains. Mycoplasmas were isolated from the throats of three pumas (Felis concolor) from the Zoological Society of London, Regents Park, London, UK (Hill, 1975). Two distinct strains were isolated from one animal (one strain was identified as $M$. arginini) and one strain isolated from each of the other two pumas. The mycoplasma from each puma was cloned to produce a pure culture, by an initial filtration of a broth culture through a $220 \mathrm{~nm}$ membrane filter, culturing of the filtrate on solid medium, transfer of a single resulting colony to a further agar plate, the subsequent growth being inoculated into broth and the whole procedure repeated a further three times, thereby cloning four times in total (Subcommittee on the Taxonomy of Mycoplasmatales, 1972). One such cloned strain was designated PU and the other two, PU1 and PU2.

Mycoplasma species. Mycoplasma type strains of 83 Mycoplasma and Acholeplasma spp. (Table 1) were obtained from the National Collection of Type Cultures, Colindale, UK and Drs H. Atobe (University of Tokyo, Japan), M. F. Barile (National Institutes of Health, Bethesda, Md., USA), J. M. Bradbury (Liverpool University, UK), R. J. Fallon (Ruchill Hospital, Glasgow, UK), E. A. Freundt (University of Aarhus, Aarhus, Denmark), J. T. Heywood (National Communicable Disease Center, Atlanta, Ga., USA), F. T. W. Jordan (Liverpool University, UK), D. E. Jasper (University of California, Davis, Calif., USA), H. Kirchoff (Tierarztliche Hochschule, Hannover, FRG), R. H. Leach (PHLS Mycoplasma Reference Laboratory, Norwich, UK), G. Smith (Zoological Society of London, London, UK), D. Taylor-Robinson (Clinical Research Centre, Harrow, UK) and J. G. Tully (National Institutes of Health, Bethesda, Md., USA).

Medium and growth conditions. The basal culture media were those described by Taylor-Robinson et al. (1968) and Hill (1971). Liquid media contained either $1 \%(\mathrm{w} / \mathrm{v})$ glucose $(\mathrm{pH} 7 \cdot 8)$ or $1 \%(\mathrm{w} / \mathrm{v})$ arginine $(\mathrm{pH} 7 \cdot 3)$ depending 


\section{Table 1. Serological tests comparing strain PU with other, named species}

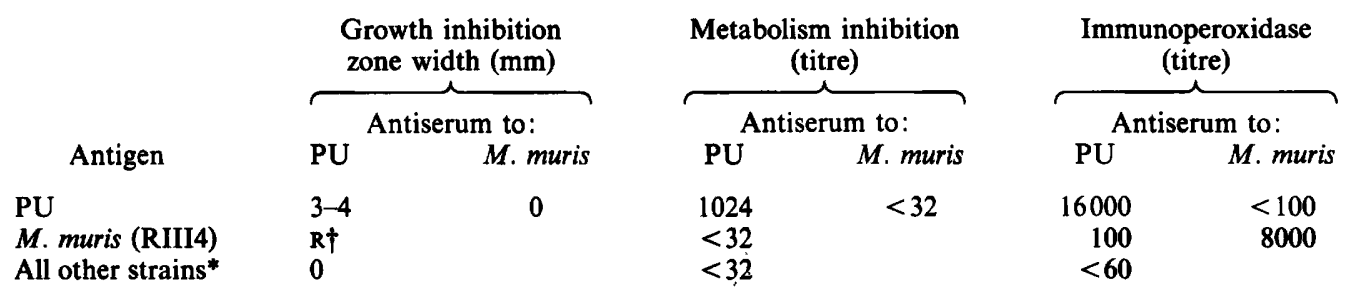

* M. agalactiae (PG2), M. alkalescens (PG51), M. alvi (Ilsley), M. anatis (1340), M. arginini (G230), M. arthritidis (PG6), M. bovigenitalium (PG11), M. bovirhinis (PG43), M. bovis (PG45), M. bovoculi (M165/69), M. buccale (CH20247), $M$. californicum (ST-6), M. canadense (275C), M. canis (PG14), M. capricolum (California kid), $M$. caviae (G122), M. cavipharyngis (117C), $M$. citelli (RG-2C), M. cloacale (383), $M$. collis (58B), $M$. columbinasale (694), $M$. columbinum (MMP1), M. columborale (MMP4), M. conjunctivae (HRC581), M. cricetuli (CH), M. cynos (H831), $M$. dispar (462/2), M. edwardii (PG24), M. equigenitalium (T37), M. equirhinis (M432/72), M. fastidiosum (4822), $M$. faucium (DC333), M. feliminutum (Ben), M. felis (CO), M. fermentans (PG18), M. flocculare (MS42), $M$. gallinaceum (DO), M. gallinarum (PG16), M. gallisepticum (PG31), M. gallopavonis (WR1), M. gateae (CS), M. genitalium (G-37), M. glycophilum (486), M. hominis (PG21), M. hyopneumoniae (J), M. hyorhinis (BTS7), $M$. hyosynoviae (S16), M. iners (PG30), M. iowae (695), M. lipofaciens (R171), M. lipophilum (MaBY), M. maculosum (PG15), M. meleagridis (17529), M. moatsii (MK405), M. molare (H542), M. mustelae (MX9), M. mycoides subsp. capri (PG3), M. mycoides subsp. mycoides (PG1), M. neurolyticum (Type A), M. opalescens (MH5408), M. orale (CH-19299), M. ovipneumoniae (Y98), M. pneumoniae (FH), M. primatum (HRC292), M. pullorum (CKK), M. pulmonis [PG34(ASH)], M. putrefaciens (KS-1), M. salivarium (PG20), M. spumans (PG13), M. sualvi [Mayfield strain (Clone B)], M. subdolum (TB), M. synoviae (WVU 1853), M. verecundum (107), A. axanthum (S743), A. equifetale (N93), A. granularum (BTS39), A. hippikon (C1), A. laidlawii (PG8), A. modicum (PG49), A. morum (72043), A. oculi (19L), A, parvum (H23M).

$\dagger \mathbf{R}$, Reduced numbers.

upon the biochemical activity of the mycoplasmas cultivated. Agar cultures were incubated at $35-37^{\circ} \mathrm{C}$ either in a humid chamber or under anaerobic conditions in a Gaspak system. Liquid cultures were stored at $-70^{\circ} \mathrm{C}$ in ampoules.

Growth requirements and characteristics. The cloned test strains were subcultured onto solid medium and grown for 1 week under both aerobic and Gaspak anaerobic conditions at $35-37^{\circ} \mathrm{C}$. Their sensitivity to methylene blue was investigated by adding $0.002 \%(\mathrm{w} / \mathrm{v})$ methylene blue to the basal solid medium and comparing the growth of inoculated mycoplasmas with those cultivated on medium without methylene blue. Lipolytic activity was tested by inoculating the mycoplasmas onto basal medium enriched with $10 \%(\mathrm{v} / \mathrm{v})$ egg yolk emulsion (Fabricant \& Freundt, 1967). The incubated plates were then examined at 3, 7 and $14 \mathrm{~d}$ for visual evidence of lipolysis (clearing) or 'film' production.

Absence of reversion. The three test strains were each subcultured, by five passages on both solid and liquid media that contained no microbial inhibitors, in order to determine whether they would revert to a bacterial form. In addition, the colonies were treated with Dienes' stain, which differentiates mycoplasma colonies from bacterial L-forms (Timms, 1967).

Morphological studies. Mycoplasma colonies grown on agar were examined microscopically at $\times 100$ magnification after 2, 7 and $14 \mathrm{~d}$ incubation. Some colonies were transferred to slides and stained with Giemsa stain (Fallon \& Whittlestone, 1969). Liquid cultures were observed under dark-field microscopy and the organisms were also examined after staining by the Giemsa method (Fallon \& Whittlestone, 1969). Organisms grown in broth were harvested by centrifugation and the resulting pellet was fixed at room temperature in $2 \%(\mathrm{v} / \mathrm{v})$ glutaraldehyde for $2 \mathrm{~h}$ and post-fixed in $1 \%(\mathrm{w} / \mathrm{v})$ osmium tetroxide for $1 \mathrm{~h}$. After embedding, thin sections were cut and stained with uranyl acetate and lead citrate (Venable \& Coggeshall, 1965) and examined by electron microscopy.

DNA base composition. DNA was extracted from centrifuged broth culture deposits by the method of Kirby (1959), and the G + C content determined from its thermal denaturation temperature (Marmur \& Doty, 1962). DNA extracted from Clostridium perfringens and Mycoplasma gallisepticum, which have known $\mathrm{G}+\mathrm{C}$ contents, were included as controls.

Filtration studies. Cultures ( $24 \mathrm{~h}$ incubation) were diluted $1 / 10$ in liquid medium, and then separate volumes of the diluted culture were filtered through membrane filters (Millipore) with pore diameters of 100, 220, 300, 450, 650 and $800 \mathrm{~nm}$. The viable count (c.f.u. $\mathrm{ml}^{-1}$ ) for each filtrate was determined and compared with that of the unfiltered culture dilution. 
Sterol dependence. Plates were prepared from serum-free medium supplemented with $0.5 \%$ bovine serum albumin (BSA), $0 \cdot 5 \%$ glucose and $10 \mu \mathrm{g}$ palmitic acid $\mathrm{ml}^{-1}$ (Razin \& Tully, 1970), to which cholesterol, dissolved in Tween 80, was added to give concentrations of $20,10,5$ and $1 \mu \mathrm{g} \mathrm{m}^{-1}$. The albumin/glucose/palmitic acid plates without cholesterol, but with and without $20 \%(\mathrm{v} / \mathrm{v})$ horse serum, were also included in the tests. Single mycoplasma colonies taken from a serum-agar plate were subcultured on the test plates and examined for growth during $14 \mathrm{~d}$ incubation $\left(35^{\circ} \mathrm{C}\right)$. Where growth occurred on any of the serum-free media, the single colonies were passaged similarly three successive times on the same medium (and also on serum-free medium without any supplements) to ensure that growth had not been due to a carry-over of serum from the original culture, giving misleading results (Razin \& Tully, 1970; Edward, 1971).

The isolates were tested indirectly for sterol dependence by a paper disc inhibition method (Freundt et al., 1973), using either dried discs originally containing $0.02 \mathrm{ml}$ of a $1.5 \%$ (w/v) ethanolic solution of digitonin (Sigma) or wet discs containing $0.02 \mathrm{ml}$ of a $20 \%(\mathrm{w} / \mathrm{v})$ aqueous solution of sodium polyanetholsulphonate (Koch-Light). The width of the zone of growth inhibition was recorded.

Biochemical activity. The three cloned strains were examined for: carbohydrate metabolism; hydrolysis of aesculin, arginine and urea (Williams \& Wittler, 1971; Leach, 1976); reduction of methylene blue, resazurin, tetrazolium and tellurite; and phosphatase activity (Tully, 1965; Aluotto et al., 1970; Barber \& Fabricant, 1971).

Erythrocyte techniques. The test strains were examined for haemolytic activity (Aluotto et al., 1970), haemadsorption and haemagglutination (Manchee \& Taylor-Robinson, 1968) with fowl, guinea pig, human and sheep erythrocytes.

Polyacrylamide gel electrophoresis. This was done as described by Razin \& Rottem (1967). Strains PU, PU1 and PU2 were compared with $M$. arginini, which has also been isolated from pumas (Hill, 1975). Centrifuged cell suspensions of the mycoplasmas were dried and $10 \mathrm{mg}$ of each suspension was dissolved in $1.0 \mathrm{ml}$ phenol/acetic acid/water $(2: 1: 0 \cdot 5$, by vol.). The gels were loaded with $0.025 \mathrm{ml}$ of the cell sample. After electrophoresis at room temperature for $3.5 \mathrm{~h}$ at a constant current of $5 \mathrm{~mA}$ per tube, the gels were stained with $1 \%(\mathrm{w} / \mathrm{v})$ naphthol blue black.

Serological studies. Antisera to mycoplasmas were prepared in rabbits as described by Morton \& Roberts (1967) and Hill (1971). The following three serological methods were used, each test being done in duplicate: growth inhibition tests with antiserum-impregnated sterile paper discs (Clyde, 1964), metabolism inhibition tests in microtitre plates (Purcell et al., 1966a, b; Taylor-Robinson et al., 1966) and immunoperoxidase tests on colonies grown on agar (Polak-Vogelzang et al., 1978).

\section{RESULTS AND DISCUSSION}

Colonies of strains PU, PU1 and PU2 were visible microscopically in subcultures after $2 \mathrm{~d}$ of incubation under both aerobic and anaerobic conditions. Primary isolates took 3-5 d to produce visible colonies. Individual colonies (Fig. 1) had a typical 'fried egg' appearance and growth was accompanied by a 'film' after prolonged incubation. Each strain produced a 'film' and clearing when cultured on egg yolk agar but the strains could not be cultured on agar containing methylene blue. Growth of the mycoplasmas was not retarded by the presence of penicillin in the medium. None of the isolates reverted to a bacterial form when serially subcultured on medium without bacterial inhibitors. Their colonies rapidly became stained with Dienes' reagent, tending to confirm these isolates as true mycoplasmas (Mollicutes) rather than as bacterial L-forms (Timms, 1967).

No motility was observed under dark-field microscopy and helical forms were not seen in any of the strains. Liquid cultures stained by the Giemsa method showed the pleomorphic forms characteristic of mycoplasmas (Boatman, 1979). The ultrastructure of the organisms in thin sections also proved typical of mycoplasma morphology (Boatman, 1979), the cells having a characteristic internal structure and being bounded by a single membrane (Fig. 2).

The DNA from strain PU was denatured at a mid-point temperature of 82.1 to $82.3{ }^{\circ} \mathrm{C}$ (corrected for thermal expansion) over several tests. The $\mathrm{G}+\mathrm{C}$ content of $31 \mathrm{~mol} \%$ was determined by the equation $T_{\mathrm{m}}=69.3+0.41(\mathrm{G}+\mathrm{C})$, where $T_{\mathrm{m}}$ is the thermal denaturation temperature (Marmur \& Doty, 1962). This value is within the known range for the Mollicutes. The $\mathrm{G}+\mathrm{C}$ contents of the controls, $C$. perfringens and $M$. gallisepticum, were the same as previously described (Marmur \& Doty, 1962).

Filtration of the liquid cultures of each test mycoplasma $\left(4 \times 10^{8}\right.$ c.f.u. $\left.\mathrm{ml}^{-1}\right)$ showed that each passed in reduced numbers through membranes with $300 \mathrm{~nm}$ pore size $\left(2 \times 10^{7}\right.$ c.f.u. $\left.\mathrm{ml}^{-1}\right)$ and $220 \mathrm{~nm}$ pore size $\left(6 \times 10^{3}\right.$ c.f.u. $\left.\mathrm{ml}^{-1}\right)$. No organisms were detected after passage through the $100 \mathrm{~nm}$ membrane. 


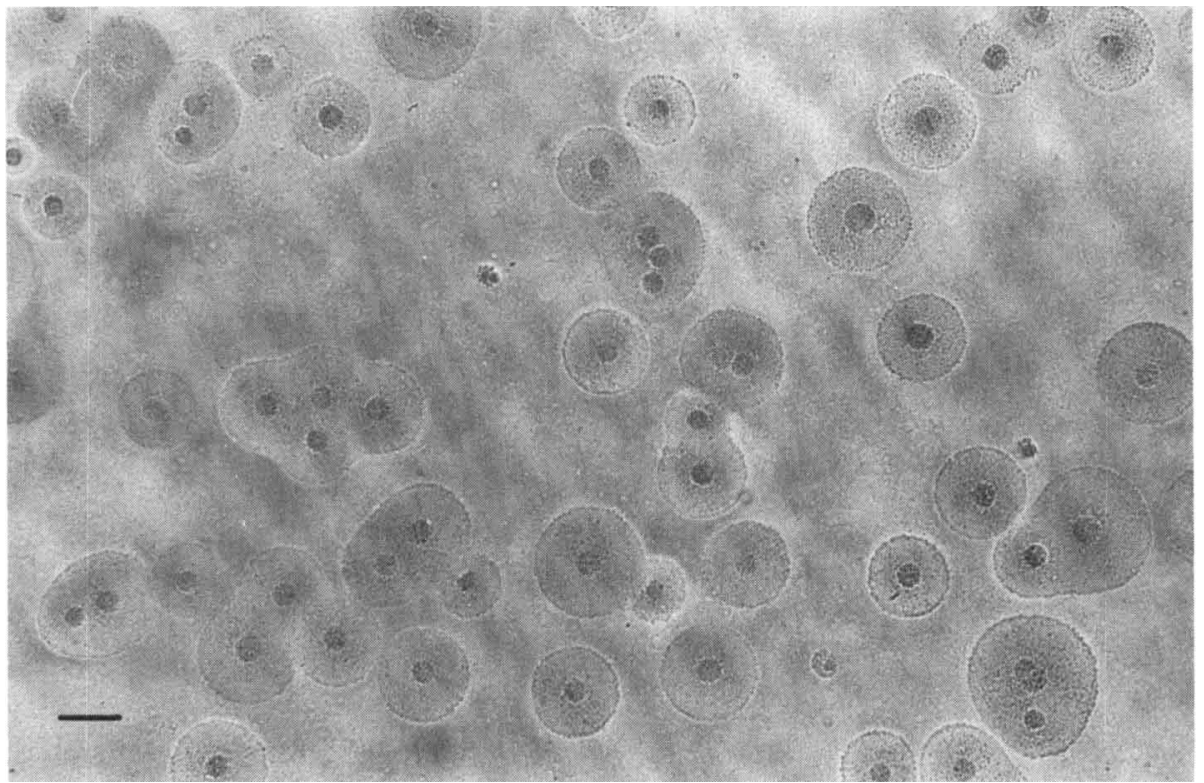

Fig. 1. Colonies of strain PU grown aerobically for $4 \mathrm{~d}$ on agar medium, as viewed by transmitted-light microscopy. Bar, $100 \mu \mathrm{m}$.

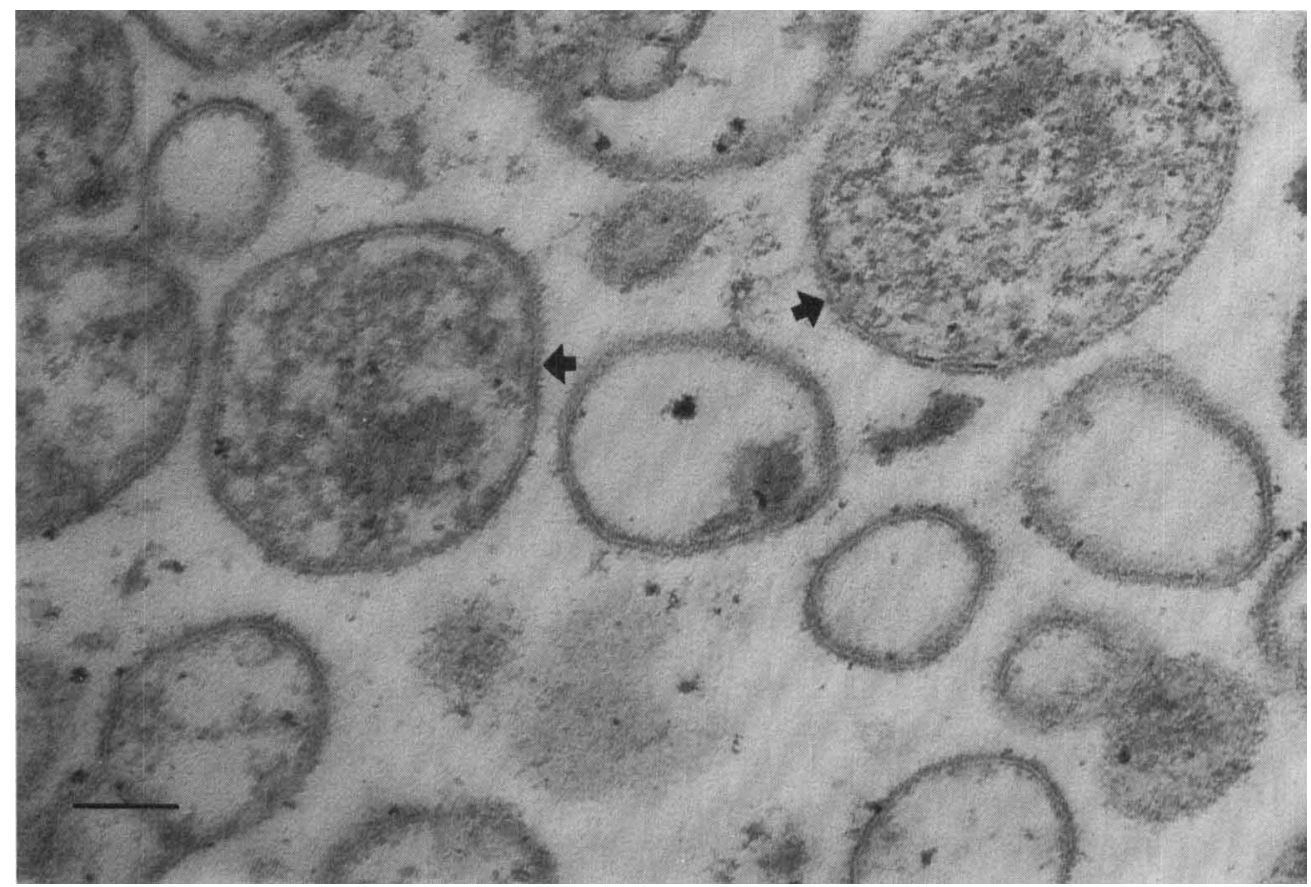

Fig. 2. Electron micrograph of a section of strain PU stained with uranyl acetate and lead citrate. Arrows indicate membrane. Bar, $400 \mathrm{~nm}$.

The three strains each required cholesterol for growth. They could not be cultured on the serum-free medium supplemented with BSA, glucose and palmitic acid without cholesterol, or with cholesterol at $1 \mu \mathrm{g} \mathrm{ml}^{-1}$, but grew and were passaged on this medium when it contained $5 \mu \mathrm{g}$ cholesterol $\mathrm{ml}^{-1}$. In conformity with their sterol-dependence, they were susceptible to 
digitonin and sodium polyanetholsulphonate in the disc tests, with large zones of growth inhibition $(>5 \mathrm{~mm})$ produced by both reagents where growth was otherwise semi-confluent.

Each strain showed identical biochemical activity. Arginine was hydrolysed but neither urea nor any carbohydrates were metabolized. Resazurin, and tellurite under anaerobic but not aerobic conditions, were reduced and phosphatase activity was demonstrated. Aesculin was not hydrolysed and nor were methylene blue or tetrazolium reduced. Casein was not digested. In appropriate tests, all three strains were haemolytic for all four types of erythrocyte tested, haemadsorbing for sheep and human cells and haemagglutinating for sheep cells only.

The three cloned strains gave similar electrophoretic protein patterns and these were distinct from that of $M$. arginini, the only identified Mycoplasma sp. yet recovered from pumas.

Each of the serological techniques showed identical levels of cross-reaction between the three cloned puma isolates. The type strain PU was reacted with antisera prepared against the species listed in Table 1. Antiserum to PU was tested with the named Mycoplasma and Acholeplasma species. No significant cross-reactions were detected, except for a slight one-way cross reaction with $M$. muris (Table 1) in growth inhibition tests, but this was not confirmed by the other two methods.

$M$. pirum was reported too recently to be included in the tests, but differs from strains PU, PU1 and PU2 in its inability to grow under aerobic conditions, in its biochemical characteristics (glucose metabolism and lack of phosphatase production), and in its lower (25.5) G $+\mathrm{C} \mathrm{mol} \mathrm{\%}$. ( $A$. florum was also omitted, having not yet been obtained by the author, but since it is a sterolindependent Acholeplasma sp. it is clearly taxonomically distinct from the sterol dependent puma isolates.)

Strains PU, PU1 and PU2 belong to the Mollicutes because of their main properties, including absence of cell walls, filterability, lack of reversion to bacterial forms when grown in antibioticfree media, penicillin resistance and production of typical morphology on agar. They belong to the genus Mycoplasma, because they are not strict anaerobes (cf. Anaeroplasma), are non-helical (cf. Spiroplasma), depend upon sterol for growth (cf. Acholeplasma), and because urease could not be demonstrated (cf. Ureaplasma).

Strains PU, PU1 and PU2 belong to the same species, as they had identical biological characteristics and showed serological and protein-pattern identity. Strain PU gave no crossreaction with any existing named species, except for a minimal one of doubtful significance with $M$. muris, which in any case has some quite distinct biological characteristics. This strain, therefore, clearly represents a new Mycoplasma species, which also contains strains PU1 and PU2. I propose that this species be named Mycoplasma felifaucium and that the type strain is PU (NCTC 11703). M. felifaucium may be a common inhabitant of the upper respiratory tract of pumas, as it was recovered from each of three animals examined. There is no evidence as to its pathogenicity, but the infected pumas showed no signs of respiratory distress.

\section{Main characteristics of Mycoplasma felifaucium}

felifaucium. feles (or felis), L. n. cat; fauces, pl. L. n. throat; felifaucium, of the feline throat. Habitat. Throat of a puma.

Morphology, physical and colony characteristics. Pleomorphic cells bounded by a single unit membrane. Colonies on agar typical 'fried egg' appearance. Filterable through $220 \mathrm{~nm}$ membrane. Resistant to penicillin.

DNA base composition. G + C content $31 \mathrm{~mol} \%$.

Growth characteristics. Aerobic and anaerobic growth. Requires sterol for growth; growth is inhibited by digitonin and sodium polyanetholsulphonate (SPS).

Optimal temperature $35-37^{\circ} \mathrm{C}$.

Metabolic characteristics. Arginine hydrolysed. No metabolism of carbohydrates.

Phosphatase produced and tetrazolium reduction negative. 'Film' positive.

Serological characteristics. Distinct from all other Mycoplasma species.

Type strain. PU (NCTC 11703).

I would like to thank J. Bird and C. Colhoun for the electron micrographs. 


\section{REFERENCES}

Aluotto, B. B., Wittler, R. G., Williams, C. O. \& FABER, J. E. (1970). Standardized bacteriologic techniques for the characterization of Mycoplasma species. International Journal of Systematic Bacteriology 20, 35-58.

BARBER, T. L. \& FABriCANT, J. (1971). Identification of Mycoplasmatales: characterization procedures. Applied Microbiology 21, 600-605.

BOATMAN, E. S. (1979). Morphology and ultrastructure of the Mycoplasmatales. In The Mycoplasmas, vol. 1, pp. 63-102. Edited by M. F. Barile \& S. Razin. New York: Academic Press.

CLYDE, W. A., JR (1964). Mycoplasma species identifcation based upon growth inhibition by specific antisera. Journal of Immunology 92, 958-965.

EDWARD, D. G. FF. (1971). Determination of sterol requirement for Mycoplasmatales. Journal of General Microbiology 69, 205-210.

FABRICANT, J. \& FREUNDT, E. A. (1967). Importance of extension and standardization of laboratory tests for the identification and classification of mycoplasma. Annals of the New York Academy of Sciences 143, 5058.

Fallon, R. J. \& Whittlestone, P. (1969). Isolation, cultivation and maintenance of mycoplasmas. Methods in Microbiology 3B, 211-267.

Freundt, E. A., ANDrews, B. E., Erno, H., Kunze M. \& BLACK, F. T. (1973). The sensitivity of mycoplasmatales to sodium-polyanethol sulfonate and digitonin. Zentralblatt für Bakteriologie. (Abteilung I, Originale A) 225, 104-112.

Heywood, J. T., Sabry, M. Z. \& Dowdle, W. R. (1969). Characterization of mycoplasma species of feline origin. American Journal of Veterinary Research 30, 615-622.

Hill, A. C. (1971). Mycoplasma caviae, a new species. Journal of General Microbiology 65, 109-113.

HiLl, A. (1975). Comparison of mycoplasmas isolated from captive wild felines. Research in Veterinary Science 18, 139-143.

KIRBY, K. S. (1959). The preparation of deoxyribonucleic acids by the $p$-aminosalicylate-phenol method. Biochimica et biophysica acta 36, 117-124.

LEACH, R. H. (1976). The inhibitory effect of arginine on growth of some mycoplasmas. Journal of Applied Bacteriology 41, 259-264.

Manchee, R. J. \& TAYloR-Robinson, D. (1968). Haemadsorption and haemagglutination by mycoplasmas. Journal of General Microbiology 50, 465478.

MARMUR, J. \& DotY, P. (1962). Determination of the base composition of deoxyribonucleic acid from its thermal denaturation temperature. Journal of Molecular Biology 5, 109-118.

Morton, H. E. \& Roberts, R. J. (1967). Production of anti-mycoplasma (PPLO) antibodies in rabbits.
Proceedings of the Society for Experimental Biology and Medicine 125, 538-543.

Polak-Vogelzang, A. A., HagenaARs, R. \& Nagel, S. (1978). Evaluation of an indirect immunoperoxidase test for identification of Acholeplasma and Mycoplasma. Journal of General Microbiology 106, 241-249.

Purcell, R. H., Taylor-Robinson, D., Wong, D. C. \& Chanock, R. M. (1966a). A color test for the measurement of antibody to the non-acid-forming human mycoplasma species. American Journal of Epidemiology 84, 51-66.

Purcell, R. H., Taylor-Robinson, D., Wong, D. C. \& Chanock, R. M. (1966b). Color test for the measurement of antibody to $\mathrm{T}$-strain mycoplasmas. Journal of Bacteriology 92, 6-12.

RAZIN, S. \& RotTEM, S. (1967). Identification of mycoplasma and other microorganisms by polyacrylamide-gel electrophoresis of cell proteins. Journal of Bacteriology 94, 1807-1810.

Razin, S. \& Tully, J. G. (1970). Cholesterol requirement of mycoplasmas. Journal of Bacteriology 102, $306-310$.

SubCommitTeE on the TAXonomy of MycoplasmaTALES (1972). Proposal for minimal standards for descriptions of new species of the order Mycoplasmatales. International Journal of Systematic Bacteriology 22, 184-188.

Taylor-Robinson, D., Purcell, R. H., Wong, D. C. \& Chanock, R. M. (1966). A colour test for the measurement of antibody to certain mycoplasma species based upon the inhibition of acid production. Journal of Hygiene 64, 91-104.

Taylor-Robinson, D., Williams, M. H. \& Haig, D. A. (1968). The isolation and comparative biological and physical characteristics of T-mycoplasmas of cattle. Journal of General Microbiology 54, 33-46.

TIMMS, L. (1967). Isolation and identification of avian mycoplasmas. Journal of Medical Laboratory Technology 24, 79-89.

TULLY, J. G. (1965). Biochemical, morphological and serological characterization of mycoplasma of murine origin. Journal of Infectious Diseases 115, 171-185.

Tully, J. G., Del Giudice, R. A. \& Barile, M. F. (1972). Synonymy of Mycoplasma arginini and Mycoplasma leonis. International Journal of Systematic Bacteriology 22, 47-49.

Venable, J. H. \& Coggeshall, R. (1965). A simplified lead citrate stain for use in electron microscopy. Journal of Cell Biology 25, 407.

Williams, C. O. \& WitTleR, R. G. (1971). Hydrolysis of aesculin and phosphatase production by members of the order Mycoplasmatales which do not require sterol. International Journal of Systematic Bacteriology 21, 73-77. 